\title{
ANALISIS BEBAN KERJA KARYAWAN PT XYZ INDONESIA PADA BAGIAN INSULATION MENGGUNAKAN METODE FULL TIME EQUIVALENT
}

\author{
Hikmah Sidiq Kurniawan \\ Program Studi Teknik Industri, Universitas Indraprasta PGRI \\ hikmahsidiqkurniawan79@gmail.com
}

Submitted November 4, 2020; Revised November 8, 2020; Accepted November 15, 2020

\begin{abstract}
Abstrak
PT XYZ Indonesia merupakan perusahaan yang bergerak dibidang manufaktur dengan memproduksi transformator daya yang bertempatkan di Jawa Barat. Dalam pelaksanaan proses produksi PT XYZ Indonesia kadang kala mengalami masalah. Masalah yang terjadi pada PT XYZ Indonesia adalah waktu proses produksi pada bagian insulation melewati waktu target yang ditentukan dikarenakan kegiatan kerja operator yang kurang produktif, maka perlu adanya perhitungan beban kerja agar mengetahui beban kerja yang didapatkan oleh operator. Tujuan dari penelitian ini yaitu meratakan beban kerja operator dan penentuan jumlah tenaga kerja agar optimal. Peneliti menggunakan metode Full Time Equivalent untuk merevisi masalah tersebut, dengan cara mengukur waktu kerja operator sehingga mengetahui nilai beban kerja yang didapatkan. Setelah dilakukan perhitungan dengan menggunakam metode tersebut, kondisi aktual di PT XYZ Indonesia mempunyai 16 operator pada bagian insulation, dengan rata-rata nilai beban kerja yang didapatkan adalah 0.34 sedangkan rekomendasi dari peneliti yaitu 9 operator bekerja pada bagian insulation dengan rata-rata nilai beban kerja yang didapatkan adalah 1.06. Sehingga mudah dalam melakukan pengawasan terhadap operator dikarenakan terjadi pengurangan atau pengalihan sebanyak 7 operator.
\end{abstract}

Kata kunci: Pengukuran Waktu Kerja, Beban Kerja, Metode Full Time Equivalent.

\section{Abstract}

PT XYZ Indonesia is a company engaged in manufacturing by producing power transformers located in west java. In the implementation of the production process of PT XYZ Indonesia, there are sometimes problems. The problem that occurs in PT XYZ Indonesia is the production process time in the insulation section exceeds the specified target time, because the operator's work activities are less productive, it is necessary to calculate workload in order to know the workload obtained by the operator. The purpose of this study is to level the operator workload and determine the number of workers to be optimal. Researchers used the full time equivalent method to revise the problem, by measuring the operator's work time so that it knows the value of the workload obtained. After calculating using this method, the actual conditions at PT XYZ Indonesia have 16 operators in the insulation section, with an average value of the workload obtained is 0.34 while the recommendation of the researchers is 9 work operators in the insulation section with an average value the workload obtained is 1.06, so that it is easy to supervise the operator due to a reduction or diversion of 7 operators.

Keywords: Measurement of Work Time, Work Load, Full Time Equivalent Method

\section{PENDAHULUAN}

Pada era globalisasi saat ini persaingan global semakin ketat, dunia perindustrian di
Indonesia semakin pesat dengan menggunakan alat dan mesin yang canggih maka dari itu sangat memerlukan tegangan listrik yang sangat besar. Ada beberapa 
perusahaan di Indonesia yang memproduksi transformator salah satunya PT XYZ Indonesia adalah perusahaan transformator terbesar di Indonesia. Sumber daya manusia (SDM) perlu diperhatikan dalam sebuah perusahaan, karena SDM merupakan faktor terpenting dalam menghasilkan suatu produk yang berkualitas. Manajemen Sumber Daya Manusia (MSDM) merupakan salah satu bidang dari manajemen umum yang meliputi segi-segi perencanaan, pengorganisasian, pelaksanaan dan pengendalian [1]. Karena sumber daya manusia (SDM) dianggap semakin penting perannya dalam pencapaian tujuan perusahaan, maka berbagai pengalaman dan hasil penelitian dalam bidang SDM dikumpulkan secara sistematis dalam apa yang disebut manajemen sumber daya manusia[1].

Pengelolaan sumber daya manusia dalam organisasi menjadi suatu bidang ilmu manajemen khusus yang dikenal dengan manajemen sumber daya manusia (MSDM)[2].

Penempatan SDM pada produksi suatu barang sangatlah penting apabila tidak sesuai akan mengakibatkan beban kerja yang kurang atau berlebihan bagi operator tersebut[2].

Beban kerja adalah suatu kondisi dari pekerjaan dengan uraian tugasnya yang harus diselesaikan pada batas waktu tertentu[3]. Beban kerja yang terlalu berlebih (overload) mengindikasikan bahwa jumlah pekerja yang dipekerjakan tidak sesuai dengan beban kerja yang diterima sehingga dapat menyebabkan kelelahan fisik maupun psikologis yang berakibat pada menurunnya produktivitas karena kelelahan bekerja[4],

Beban kerja yang berlebihan juga dapat berakibat buruk pada kualitas dan performasi, contoh seperti penurunan waktu reaksi, peningkatan kesalahan dalam mengambil keputusan, penurunan kemampuan untuk berkonsentrasi serta peningkatanpotensi kecelakaan kerja"[5]. Sedangkan beban kerja yang terlalu rendah (underload) mengindikasikan bahwa jumlah pekerja yang dipekerjakan terlalu banyak sehingga perusahaan harusmengalokasikan biaya untuk gaji karyawanlebih banyak dengan tingkat produktivitas yang sama [6]. Beban kerja yang diberikan kepada karyawan terdapat tiga kondisi yaitu fit (beban kerja sesuai standar), overload (beban kerja tinggi) dan underload (beban kerja rendah) [7].

Ada beberapa penyebab yang menimbulkan suatu masalah dalam perusahaan seperti material, manusia, mesin, metode dan biaya. Pada penelitian kali ini peneliti lebih berfokus pada masalah manusia karena jumlah tenaga kerja yang belum sesuai dan beban kerja yang dimiliki oleh operator perlu dioptimalkan[8].

Tabel 1.Waktu Target dan Aktual Pembuatan Transformator 30 MVA -02

\begin{tabular}{|c|c|c|c|c|}
\hline NO & Description & $\begin{array}{c}\text { Target } \\
\text { (jam) }\end{array}$ & $\begin{array}{c}\text { Aktual } \\
\text { (jam) }\end{array}$ & $\begin{array}{c}\text { Selisih } \\
\text { (jam) }\end{array}$ \\
\hline 1 & Insulation & 328 & 355 & 27 \\
\hline 2 & Winding & 435 & 453 & 18 \\
\hline 3 & Core Stacking & 135 & 154 & 19 \\
\hline 4 & Core Coil & 218 & 214 & -4 \\
\hline 5 & $\begin{array}{c}\text { Lead } \\
\text { Connection }\end{array}$ & 86 & 98 & 12 \\
\hline \multirow[t]{2}{*}{6} & $\begin{array}{c}\text { Final } \\
\text { Assembly }\end{array}$ & 115 & 134 & 19 \\
\hline & Jumlah & 1317 & 1408 & 91 \\
\hline
\end{tabular}

Sumber : PT XYZ Indonesia

Dari tabel 1 waktu target dan waktu aktual memiliki selisih yang lumayan jauh yaitu 91 jam lebih lambat dalam memproduksi suatu transformator. Dapat dilihat angka selisih tertinggi terdapat pada stasiun kerja insulation maka dari itu peneliti memilih melakukan penelitian beban kerja pada bagian stasiun kerja insulation, karena pada stasiun ini sangat mempengaruhi ke stasiun-stasiun selanjutnya. Untuk 
memecahkan masalah beban kerja perlu adanya metode yang benar-benar tepat untuk mengukur beban kerja dari operator.

\section{METODE PENELITIAN}

Untuk teknik analisis data terdapat langkahlangkah sebagai berikut [9]:

\section{A. Observasi}

Observasi dilakukan pada bagian insulation dengan mengamati elemenelemen kerja operator dan waktu siklus yang dikerjakan. Penelitian ini hanya melakukan pengamatan pada tiga komponen yaitu frame, press block dan screen.

B. Wawancara

Pada penelitian ini wawancara dilakukan pada operator, staf dan kepala gudang, atas persetujuan HRD dengan tujuan agar mendapatkan informasi dan pengetahuan yang dibutuhkan oleh peneliti.

C. Dokumentasi

Melakukan teknik dokumentasai dimana peneliti mengambil data karakteristik pekerja, permintaan dan perencanaan perusahaan. Pengumpulan data

Pengumpulan data primer terkait deskripsi pekerjaan, spesifikasi pekerjaan, rata-rata waktu penyelesaian tugas, dan kuantitas beban tugas diperoleh melalui pengamatan. Data terkait pengukuran beban kerja dengan metode FTE yaitu sebagai berikut :

1) Tentukan jumlah waktu kerja karyawan dalam satu tahun 2018.

2) Tentukan jumlah jam kerja karyawan dalam satu hari.
3) Tentukan jumlah hari kerja karyawan dalam satu minggu.

4) Tentukan jumlah hari cuti karyawan dan libur nasional dalam satu tahun 2018.

5) Tentukan status karyawan.

6) Menentukan elemen pekerjaan dan komponen yang diambil.

7) Mencari waktu siklus dan waktu normal.

D. Pengolahan data

Berukut adalah data yang dicari dalam tahapan pengolahan data pada penelitian ini dengan menggunakan metode FTE:

1) Waktu siklus

2) Uji Keseragaman

3) Uji Kecukupan

4) Rating factor

5) Waktu normal

6) Nilai Full Time Equivalent (FTE)

7) Rekomendasi Full Time Equivalent (FTE)

E. Analisis data

Analisis data dilakukan dengan melakukan dengan menentukan waktu siklus, waktu normal, dan penentuan nilai FTE. ditunjukkan dengan rumus berikut [10]:

$\operatorname{Waktu} \operatorname{Siklus}(W s)=\frac{\sum X 1}{N}$

Waktu normal $(W n)=W s \times$

Penyesuaian

Total jam elemen $\left(\frac{\text { hours }}{\text { year }}\right)=$

$\underline{\text { Frekuensi kegiatan } \times \mathrm{Wn} \times \text { jumlah hari keja }}$ 3600

FTE

$=\frac{\text { Total jam kerja elemen per tahun }+ \text { Allowance }}{\text { Waktu jam kerja efektif per tahun }}$ 


\section{HASIL DAN PEMBAHASAN}

Metode perhitungan beban kerja dengan full time equivalent (FTE) adalah metode dimana waktu yang digunakan untuk menyelesaikan berbagai pekerjaan dibandingkan terhadap waktu kerja efektif yang tersedia. FTE bertujuan menyederhanakan pengukuran kerja dengan mengubah jam beban kerja ke jumlah orang yang dibutuhkan untuk menyelesaikan pekerjaan tertentu [7]. Tahapan untuk mendapatkan nilai FTE dari suatu proses kerja adalah sebagai berikut :

\section{Waktu Siklus, Uji Keseragaman dan Uji Kecukupan Data}

Berikut adalah nilai waktu siklus (menit) yang didapatkan dari pengamatan semua operator pada bagian insulation beseta uji keseragaman dan uji kecukupan data:

Tabel 2. Waktu Siklus, Uji Keseragaman dan Uji Kecukupan Data

\begin{tabular}{|c|c|c|c|c|c|c|c|c|}
\hline Operator & No & Nama Kegiatan & $\begin{array}{l}\text { waktu } \\
\text { siklus }\end{array}$ & BKA & BKB & $\mathbf{N}$ & $\mathbf{N}^{\prime}$ & Keterangan \\
\hline \multirow{4}{*}{$\begin{array}{c}\text { Operator } 1 \\
\text { (pemotongan) }\end{array}$} & 1 & Pengambilan bahan baku & 7.2 & 7.43 & 7.23 & 30 & 3.88 & Cukup \\
\hline & 2 & Pengukuran bahan baku & 10.21 & 10.43 & 10.19 & 30 & 1.39 & Cukup \\
\hline & 3 & Pemrograman mesin & 6.36 & 6.42 & 6.20 & 30 & 6.07 & Cukup \\
\hline & 4 & Pemotongan bahan baku & 22.31 & 22.39 & 22.15 & 30 & 0.14 & Cukup \\
\hline \multirow{4}{*}{$\begin{array}{c}\text { Operator } 2 \\
\text { (pemotongan) }\end{array}$} & 1 & Pengambilan bahan baku & 7.38 & 7.45 & 7.23 & 30 & 3.86 & Cukup \\
\hline & 2 & Pengukuran bahan baku & 9.22 & 9.42 & 9.20 & 30 & 1.89 & Cukup \\
\hline & 3 & Pemrograman mesin & 7.25 & 7.40 & 7.18 & 30 & 3.94 & Cukup \\
\hline & 4 & Pemotongan bahan baku & 23.21 & 23.44 & 23.16 & 30 & 0.12 & Cukup \\
\hline \multirow{4}{*}{$\begin{array}{c}\text { Operator } 3 \\
\text { (pemotongan) }\end{array}$} & 1 & Pengambilan bahan baku & 6.36 & 6.44 & 6.19 & 30 & 6.05 & Cukup \\
\hline & 2 & Pengukuran bahan baku & 9.37 & 9.43 & 9.17 & 30 & 1.90 & Cukup \\
\hline & 3 & Pemrograman mesin & 7.4 & 7.40 & 7.16 & 30 & 3.96 & Cukup \\
\hline & 4 & Pemotongan bahan baku & 22.48 & 22.49 & 22.26 & 30 & 0.14 & Cukup \\
\hline \multirow{4}{*}{$\begin{array}{c}\text { Operator } 4 \\
\text { (Pemotongan) }\end{array}$} & 1 & Pengambilan bahan baku & 7.51 & 7.51 & 7.29 & 30 & 3.77 & Cukup \\
\hline & 2 & Pengukuran bahan baku & 8.26 & 8.44 & 8.20 & 30 & 2.65 & Cukup \\
\hline & 3 & Pemrograman mesin & 6.36 & 6.47 & 6.21 & 30 & 5.99 & Cukup \\
\hline & 4 & Pemotongan bahan baku & 21.42 & 21.46 & 21.24 & 30 & 0.16 & Cukup \\
\hline \multirow{5}{*}{$\begin{array}{l}\text { Operator } 5 \\
\text { (Pengeboran) }\end{array}$} & 1 & Pengambilan pisau bor & 4.27 & 4.45 & 4.25 & 30 & 4.25 & Cukup \\
\hline & 2 & Pemasangan pisau bor & 12.34 & 12.42 & 12.19 & 30 & 0.82 & Cukup \\
\hline & 3 & Pengambilan komponen & 8.37 & 8.43 & 8.20 & 30 & 2.65 & Cukup \\
\hline & 4 & Pemasangan komponen & 9.25 & 9.40 & 9.16 & 30 & 1.91 & Cukup \\
\hline & 5 & Pengeboran komponen & 13.29 & 13.40 & 13.18 & 30 & 0.65 & Cukup \\
\hline
\end{tabular}




\begin{tabular}{|c|c|c|c|c|c|c|c|c|}
\hline Operator & No & Nama Kegiatan & $\begin{array}{l}\text { waktu } \\
\text { siklus }\end{array}$ & BKA & BKB & $\mathbf{N}$ & $\mathbf{N}^{\prime}$ & Keterangan \\
\hline \multirow{5}{*}{$\begin{array}{c}\text { Operator } 6 \\
\text { (Pengeboran) }\end{array}$} & 1 & Pengambilan pisau bor & 4.19 & 4.36 & 4.18 & 30 & 19.63 & Cukup \\
\hline & 2 & Pemasangan pisau bor & 11.39 & 11.47 & 11.24 & 30 & 1.04 & Cukup \\
\hline & 3 & Pengambilan komponen & 8.26 & 8.48 & 8.26 & 30 & 2.60 & Cukup \\
\hline & 4 & Pemasangan komponen & 8.45 & 8.46 & 8.26 & 30 & 2.61 & Cukup \\
\hline & 5 & Pengeboran komponen & 12.45 & 12.47 & 12.27 & 30 & 0.81 & Cukup \\
\hline \multirow{5}{*}{$\begin{array}{c}\text { Operator } 7 \\
\text { (Pengeboran) }\end{array}$} & 1 & Pengambilan pisau bor & 4.51 & 4.51 & 4.31 & 30 & 17.79 & Cukup \\
\hline & 2 & Pemasangan pisau bor & 11.33 & 11.47 & 11.25 & 30 & 1.04 & Cukup \\
\hline & 3 & Pengambilan komponen & 8.48 & 8.50 & 8.28 & 30 & 2.58 & Cukup \\
\hline & 4 & Pemasangan komponen & 9.31 & 9.46 & 9.25 & 30 & 1.86 & Cukup \\
\hline & 5 & Pengeboran komponen & 14.19 & 14.42 & 14.18 & 30 & 0.52 & Cukup \\
\hline \multirow{3}{*}{$\begin{array}{c}\text { Operator } 8 \\
\text { (Pengamplasan) }\end{array}$} & 1 & Pengambilan bahan baku & 4.27 & 4.44 & 4.20 & 30 & 18.89 & Cukup \\
\hline & 2 & Pemrograman mesin & 9.2 & 9.43 & 9.19 & 30 & 1.89 & Cukup \\
\hline & 3 & Proses Pengamplasan & 10.15 & 10.38 & 10.15 & 30 & 1.41 & Cukup \\
\hline \multirow{3}{*}{$\begin{array}{c}\text { Operator } 9 \\
\text { (Pengamplasan) }\end{array}$} & 1 & Pengambilan bahan baku & 4.18 & 4.36 & 4.17 & 30 & 19.63 & Cukup \\
\hline & 2 & Pemrograman mesin & 8.34 & 8.44 & 8.25 & 30 & 2.63 & Cukup \\
\hline & 3 & Proses Pengamplasan & 11.49 & 11.50 & 11.27 & 30 & 1.03 & Cukup \\
\hline \multirow{5}{*}{$\begin{array}{c}\text { Operator } 10 \\
\text { (Penghalusan) }\end{array}$} & 1 & Pengambilan pisau bor & 4.15 & 4.37 & 4.15 & 30 & 19.68 & Cukup \\
\hline & 2 & Pemasangan pisau bor & 5.17 & 5.43 & 5.11 & 30 & 10.39 & Cukup \\
\hline & 3 & Pengambilan komponen & 4.24 & 4.46 & 4.22 & 30 & 18.61 & Cukup \\
\hline & 4 & Pemasangan komponen & 4.42 & 4.47 & 4.24 & 30 & 18.44 & Cukup \\
\hline & 5 & Penghalusan komponen & 7.15 & 7.34 & 7.15 & 30 & 4.02 & Cukup \\
\hline \multirow{5}{*}{$\begin{array}{c}\text { Operator } 11 \\
\text { (Penghalusan) }\end{array}$} & 1 & Pengambilan pisau bor & 4.18 & 4.36 & 4.16 & 30 & 19.77 & Cukup \\
\hline & 2 & Pemasangan pisau bor & 4.37 & 4.41 & 4.24 & 30 & 18.86 & Cukup \\
\hline & 3 & Pengambilan komponen & 4.19 & 4.39 & 4.17 & 30 & 19.50 & Cukup \\
\hline & 4 & Pemasangan komponen & 5.16 & 5.35 & 5.15 & 30 & 10.53 & Cukup \\
\hline & 5 & Penghalusan komponen & 7.08 & 7.38 & 7.16 & 30 & 3.98 & Cukup \\
\hline \multirow{2}{*}{$\begin{array}{c}\text { Operator } 12 \\
\text { (Pengeleman) }\end{array}$} & 1 & Pengambilan bahan baku & 7.22 & 7.44 & 7.21 & 30 & 3.89 & Cukup \\
\hline & 2 & Proses Pengeleman & 17.17 & 17.36 & 17.16 & 30 & 0.30 & Cukup \\
\hline \multirow{2}{*}{$\begin{array}{c}\text { Operator } 13 \\
\text { (Pengeleman) }\end{array}$} & 1 & Pengambilan bahan baku & 6.52 & 6.52 & 6.31 & 30 & 5.79 & Cukup \\
\hline & 2 & Proses Pengeleman & 18.38 & 18.44 & 18.20 & 30 & 0.25 & Cukup \\
\hline
\end{tabular}




\begin{tabular}{|c|c|c|c|c|c|c|c|c|}
\hline Operator & No & Nama Kegiatan & $\begin{array}{l}\text { waktu } \\
\text { siklus }\end{array}$ & BKA & BKB & $\mathbf{N}$ & $\mathbf{N}^{\prime}$ & Keterangan \\
\hline \multirow{3}{*}{$\begin{array}{c}\text { Operator } 14 \\
\text { (Bending) }\end{array}$} & 1 & Seting mesin & 13.44 & 13.46 & 13.23 & 30 & 0.64 & Cukup \\
\hline & 2 & Pengambilan bahan baku & 6.26 & 6.45 & 6.21 & 30 & 6.01 & Cukup \\
\hline & 3 & Proses bending & 22.15 & 22.37 & 22.14 & 30 & 0.14 & Cukup \\
\hline \multirow{3}{*}{$\begin{array}{l}\text { Operator } 15 \\
\text { (Bending) }\end{array}$} & 1 & Seting mesin & 14.44 & 14.46 & 14.24 & 30 & 0.52 & Cukup \\
\hline & 2 & Pengambilan bahan baku & 6.28 & 6.45 & 6.22 & 30 & 6.00 & Cukup \\
\hline & 3 & Proses bending & 21.47 & 21.47 & 21.21 & 30 & 0.16 & Cukup \\
\hline \multirow{3}{*}{$\begin{array}{c}\text { Operator } 16 \\
\text { (Bending) }\end{array}$} & 1 & Seting mesin & 15.22 & 15.45 & 15.21 & 30 & 0.42 & Cukup \\
\hline & 2 & Pengambilan bahan baku & 7.38 & 7.45 & 7.23 & 30 & 3.86 & Cukup \\
\hline & 3 & Proses bending & 19.41 & 19.48 & 19.28 & 30 & 0.21 & Cukup \\
\hline
\end{tabular}

Setelah dilakukannya uji keseragaman dan uji kecukupan, waktu siklus dari kegiatan kerja terbukti cukup maka selanjutnya data akan dihitung dengan menggunakan metode full time equivalent untuk memecahkan masalah beban kerja pada operator bagian insulation.

\section{Waktu Normal}

Dalam melakukan pekerjaan, secara umum kemampuan operator berbeda-beda, tidak semua operator melakukan kegiatan kerja yang sama dan menghasilkan waktu yang sama dengan operator lainnya. Maka perlu adanya perhitungan waktu normal agar operator dapat mengetahui batas waktu dalam melakukan kegiatan kerja. Berikut ini adalah hasil dari perhitungan waktu normal kegiatan kerja operator PT XYZ Indonesia pada bagian Insulation:

Tabel 3. Waktu Normal

\begin{tabular}{cclccc}
\hline Operator & No & \multicolumn{1}{c}{ Nama Kegiatan } & $\begin{array}{c}\text { Rating } \\
\text { Faktor }\end{array}$ & $\begin{array}{c}\text { Waktu } \\
\text { Siklus }\end{array}$ & $\begin{array}{c}\text { Waktu } \\
\text { Normal }\end{array}$ \\
& 1 & Pengambilan bahan baku & 1.14 & 7.2 & 8.21 \\
Operator 1 & 2 & Pengukuran bahan baku & 1.11 & 10.21 & 11.33 \\
(pemotongan) & 3 & Pemrograman mesin & 1.15 & 6.36 & 7.31 \\
& 4 & Pemotongan bahan baku & 1.12 & 22.31 & 24.99 \\
\hline & 1 & Pengambilan bahan baku & 1.17 & 7.38 & 8.63 \\
Operator 2 & 2 & Pengukuran bahan baku & 1.09 & 9.22 & 10.05 \\
(pemotongan) & 3 & Pemrograman mesin & 1.16 & 7.25 & 8.41 \\
& 4 & Pemotongan bahan baku & 1.15 & 23.21 & 26.69 \\
\hline & 1 & Pengambilan bahan baku & 1.13 & 6.36 & 7.19 \\
Operator 3 & 2 & Pengukuran bahan baku & 1.14 & 9.37 & 10.68 \\
(pemotongan) & 3 & Pemrograman mesin & 1.12 & 7.4 & 8.29 \\
& 4 & Pemotongan bahan baku & 1.13 & 22.48 & 25.40 \\
\hline & 1 & Pengambilan bahan baku & 1.14 & 7.51 & 8.56 \\
& 2 & Pengukuran bahan baku & 1.1 & 8.26 & 9.09 \\
Operator 4 & 3 & Pemrograman mesin & 1.13 & 6.36 & 7.19 \\
(Pemotongan) & 4 & Pemotongan bahan baku & 1.14 & 21.42 & 24.42 \\
\hline
\end{tabular}




\begin{tabular}{|c|c|c|c|c|c|}
\hline Operator & No & Nama Kegiatan & $\begin{array}{l}\text { Rating } \\
\text { Faktor }\end{array}$ & $\begin{array}{l}\text { Waktu } \\
\text { Siklus }\end{array}$ & $\begin{array}{c}\text { Waktu } \\
\text { Normal }\end{array}$ \\
\hline \multirow{5}{*}{$\begin{array}{c}\text { Operator } 5 \\
\text { (Pengeboran) }\end{array}$} & 1 & Pengambilan pisau bor & 1.15 & 4.27 & 4.91 \\
\hline & 2 & Pemasangan pisau bor & 1.09 & 12.34 & 13.45 \\
\hline & 3 & Pengambilan komponen & 1.12 & 8.37 & 9.37 \\
\hline & 4 & Pemasangan komponen & 1.08 & 9.25 & 9.99 \\
\hline & 5 & Pengeboran komponen & 1.13 & 13.29 & 15.02 \\
\hline \multirow{5}{*}{$\begin{array}{c}\text { Operator } 6 \\
\text { (Pengeboran) }\end{array}$} & 1 & Pengambilan pisau bor & 1.11 & 4.19 & 4.65 \\
\hline & 2 & Pemasangan pisau bor & 1.1 & 11.39 & 12.53 \\
\hline & 3 & Pengambilan komponen & 1.11 & 8.26 & 9.17 \\
\hline & 4 & Pemasangan komponen & 1.15 & 8.45 & 9.72 \\
\hline & 5 & Pengeboran komponen & 1.2 & 12.45 & 14.94 \\
\hline \multirow{5}{*}{$\begin{array}{c}\text { Operator } 7 \\
\text { (Pengeboran) }\end{array}$} & 1 & Pengambilan pisau bor & 1.1 & 4.51 & 4.96 \\
\hline & 2 & Pemasangan pisau bor & 1.09 & 11.33 & 12.35 \\
\hline & 3 & Pengambilan komponen & 1.13 & 8.48 & 9.58 \\
\hline & 4 & Pemasangan komponen & 1.13 & 9.31 & 10.52 \\
\hline & 5 & Pengeboran komponen & 1.19 & 14.19 & 16.89 \\
\hline \multirow{3}{*}{$\begin{array}{c}\text { Operator } 8 \\
\text { (Pengamplasan) }\end{array}$} & 1 & Pengambilan bahan baku & 1.12 & 4.27 & 4.78 \\
\hline & 2 & Pemrograman mesin & 1.13 & 9.2 & 10.40 \\
\hline & 3 & Proses Pengamlasan & 1.15 & 10.15 & 11.67 \\
\hline \multirow{3}{*}{$\begin{array}{c}\text { Operator } 9 \\
\text { (Pengamplasan) }\end{array}$} & 1 & Pengambilan bahan baku & 1.12 & 4.18 & 4.68 \\
\hline & 2 & Pemrograman mesin & 1.14 & 8.34 & 9.51 \\
\hline & 3 & Proses Pengamlasan & 1.13 & 11.49 & 12.98 \\
\hline \multirow{5}{*}{$\begin{array}{c}\text { Operator } 10 \\
\text { (Penghalusan) }\end{array}$} & 1 & Pengambilan pisau bor & 1.12 & 4.15 & 4.65 \\
\hline & 2 & Pemasangan pisau bor & 1.16 & 5.17 & 6.00 \\
\hline & 3 & Pengambilan komponen & 1.12 & 4.24 & 4.75 \\
\hline & 4 & Pemasangan komponen & 1.11 & 4.42 & 4.91 \\
\hline & 5 & Penghalusan komponen & 1.13 & 7.15 & 8.08 \\
\hline \multirow{5}{*}{$\begin{array}{c}\text { Operator } 11 \\
\text { (Penghalusan) }\end{array}$} & 1 & Pengambilan pisau bor & 1.1 & 4.18 & 4.60 \\
\hline & 2 & Pemasangan pisau bor & 1.16 & 4.37 & 5.07 \\
\hline & 3 & Pengambilan komponen & 1.13 & 4.19 & 4.73 \\
\hline & 4 & Pemasangan komponen & 1.1 & 5.16 & 5.68 \\
\hline & 5 & Penghalusan komponen & 1.12 & 7.08 & 7.93 \\
\hline \multirow{2}{*}{$\begin{array}{c}\text { Operator } 12 \\
\text { (Pengeleman) }\end{array}$} & 1 & Pengambilan bahan baku & 1.17 & 7.22 & 8.45 \\
\hline & 2 & Proses Pengeleman & 1.15 & 17.17 & 19.75 \\
\hline \multirow{2}{*}{$\begin{array}{c}\text { Operator } 13 \\
\text { (Pengeleman) }\end{array}$} & 1 & Pengambilan bahan baku & 1.1 & 6.52 & 7.17 \\
\hline & 2 & Proses Pengeleman & 1.12 & 18.38 & 20.59 \\
\hline \multirow{3}{*}{$\begin{array}{l}\text { Operator } 14 \\
\text { (Bending) }\end{array}$} & 1 & Seting mesin & 1.13 & 13.44 & 15.19 \\
\hline & 2 & Pengambilan bahan baku & 1.12 & 6.26 & 7.01 \\
\hline & 3 & Proses bending & 1.11 & 22.15 & 24.59 \\
\hline \multirow{3}{*}{$\begin{array}{l}\text { Operator } 15 \\
\text { (Bending) }\end{array}$} & 1 & Seting mesin & 1.2 & 14.44 & 17.33 \\
\hline & 2 & Pengambilan bahan baku & 1.12 & 6.28 & 7.03 \\
\hline & 3 & Proses bending & 1.15 & 21.47 & 24.69 \\
\hline \multirow{3}{*}{$\begin{array}{l}\text { Operator } 16 \\
\text { (Bending) }\end{array}$} & 1 & Seting mesin & 1.18 & 15.22 & 17.96 \\
\hline & 2 & Pengambilan bahan baku & 1.17 & 7.38 & 8.63 \\
\hline & 3 & Proses bending & 1.12 & 19.41 & 21.74 \\
\hline
\end{tabular}




\section{Perbandingan Full Time Equivalent Aktual dan Rekomendasi}

Tabel berikut adalah hasil dari perhitungan beban kerja aktual dan rekomendasi dengan menggunakan metode full time equivalent dari setiap operator kerja pada bagian insulation sebagai berikut:

Tabel 4.Perbandingan Full Time Equivalent Aktual dan Rekomendasi

\begin{tabular}{cccc}
\hline $\begin{array}{c}\text { Jumlah } \\
\text { Pekerja }\end{array}$ & $\begin{array}{c}\text { FTE } \\
\text { max }\end{array}$ & $\begin{array}{c}\text { Nilai FTE } \\
\text { (Aktual) }\end{array}$ & $\begin{array}{c}\text { Nilai FTE } \\
\text { (Rekomen- } \\
\text { dasi) }\end{array}$ \\
\hline Operator 1 & 1.28 & 0.29 & 1.20 \\
Operator 2 & 1.28 & 0.31 & 1.15 \\
Operator 3 & 1.28 & 0.29 & 0.9 \\
Operator 4 & 1.28 & 0.28 & 0.9 \\
Operator 5 & 1.28 & 0.4 & 1.23 \\
Operator 6 & 1.28 & 0.39 & 1.28 \\
Operator 7 & 1.28 & 0.41 & 1.27 \\
Operator 8 & 1.28 & 0.31 & 0.81 \\
Operator 9 & 1.28 & 0.31 & 0.83 \\
Operator 10 & 1.28 & 0.32 & \\
Operator 11 & 1.28 & 0.32 & \\
Operator 12 & 1.28 & 0.32 & \\
Operator 13 & 1.28 & 0.32 & \\
Operator 14 & 1.28 & 0.36 & \\
Operator 15 & 1.28 & 0.37 & \\
Operator 16 & 1.28 & 0.37 & $\mathbf{1 . 0 6}$ \\
$\overline{\boldsymbol{X}}$ & & $\mathbf{0 . 3 4}$ & \\
\hline & & Sumber : Pengolahan Data
\end{tabular}

Dari tabel 4 dijelaskan bahwa beban kerja aktual yang didapatkan operator 1 sampai dengan operator 16 dengan nilai rata-rata FTE yang didapatkan sebesar 0.34 masih sangat jauh dengan nilai FTE yang normal yaitu dengan nilai $0.99-1.28$ maka perlu adanya penambahan beban kerja dan penentuan jumlah operator yang optimal pada bagian insulation. Rekomendasi jumlah operator pada bagian insulation dari 16 operator menjadi 9 operator dan bertambahnya nilai rata-rata FTE yang didapatkan operator dari 0.34 menjadi 1.06 sehingga jumlah tenaga kerja dan beban kerja yang didapatkan operator pada bagian insulation sudah optimal. Berikut diagram Perbandingan Full Time Equivalent Aktual dan Rekomendasi yang didapatkan operator bagian insulation:

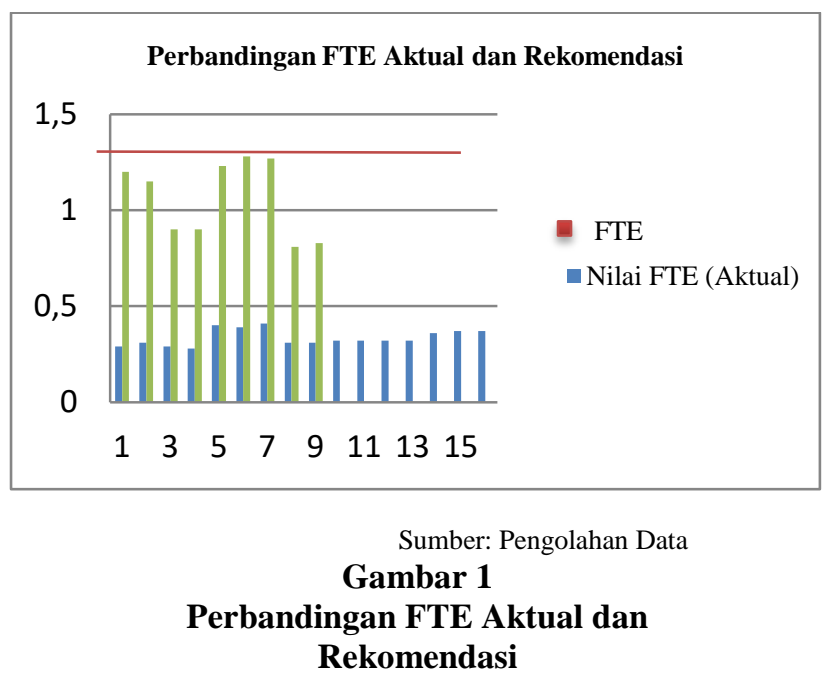

Dapat dilihat dari gambar 1 terjadi perubahan pada beban kerja yang didapatkan operator yang menjadi merata dan jumlah tenaga kerja yang optimal, dari 16 operator menjadi 9 operator, sehingga perusahaan bisa mengefisiensi biaya (gaji) dan mempermudah dalam pengawasan pada saat operator dibagian insulation bekerja

\section{SIMPULAN}

Dari perhitungan yang telah dilakuakan dengan metode full time equivalent, nilai beban kerja aktual di PT XYZ Indonesia memiliki rata-rata beban kerja yang didapatkan setiap operator pada bagian insulation adalah 0.34 , nilai beban kerja tersebut tergolong beban kerja yang rendah (underload) maka perlu adanya perhitungan kembali. Setelah dilakukan perhitungan nilai beban kerja rekomendasi memiliki rata-rata beban kerja yang didapatkan setiap operator pada bagian insulation adalah 1.06, nilai tersebut 
tergolong normal (fit).Rekomendasi jumlah tenaga kerja dari penelitian ini menjadi 9 operator pada bagian insulation, dua operator pada bagian pemotongan, dua operator pada bagian pengeboran, satu operator pada bagian pengamplasan, satu operator pada bagian penghalusan, satu operator pada bagian pengeleman dan dua operator pada bagian bending dengan ratarata nilai beban kerja yang didapatkan adalah 1.06, nilai beban kerja tersebut tergolong beban kerja yang normal (fit). Maka terjadi pengurangan atau pengalihan tenaga kerja sebanyak 7 kebagian yang lebih membutuhkan.

\section{DAFTAR PUSTAKA}

[1] Hanan, M., \& Yusuf, W. (n.d.). Workload Analysis Dengan Metode Full Time Equivalent ( Fte ) Untuk Menentukan Kebutuhan Tenaga Kerja Pada Dept . Produksi Unit Betalactam. $1-8$.

[2] Prima, A. A. (n.d.). Jurnal PASTI Volume XII No. 2, 154 - 168 Analisis Beban Kerja Terhadap Tenaga Kerja Analis Kimia Dengan Metode Full Time Equivalent Di Divisi Technology Development Departemen $R \& D$ Analytical Development PT XYZ. XII(2), 154-168.

[3] Munandar, A, S., (2008) PsikologiIndustri Dan Organisasi. Jakarta: Universitas Indonesia Press

[4] Sedarmayanti., (2009) Tata Kerja Produktivitas Kerja.Cetakan Kedua. Bandung: Mandar Maju.
[5] Iridiastadi, H \&Yassierli (2017) Ergonomi Suatu Pengantar. Bandung: PT Remaja Rosdakarya

[6] N, M. G. A. (2017). Efektivitas Manpower Planning Dengan Menggunakan Metode Analisis Beban Kerja ( Work Load Analysis ) Berdasarkan Pendekatan Full Time Equivalent ( Studi Pada Divisi Pengembangan Karir, Organisasi, dan Kompetensi di PT . Pupuk. Jurnal Administrasi Bisnis, 42(1), 27-35.

[7]Tridoyo, S. (2014). Analisis Beban Kerja Dengan Metode Full Time Equivalent Untuk Mengoptimalkan Kinerja Karyawan Pada Pt Astra International Tbk-Honda Sales Operation Region Semarang. 1-8.

[8] Tawarka.,(2011) Ergonomi Industri: Dasar-dasar Pengetahuan Ergonomi Dan Aplikasi Di Tempat Kerja. Edisi Revisi. Solo: Harapan Press.

[9] Fahmy, A., R, B. M., \& Amrullah, H. N. (2018). Analisis Beban Kerja Dengan Metode Full Time Equivalent Untuk Mengoptimalkan Kinerja Pada Teknisi Maintenance Rtg. 2581, 503506.

[10] Silvia, N., Putri, H., \& Purnomo, H. (2018). Penentuan Jumlah Karyawan Dengan Metode Full Time Equivalent (Fte) (Studi Kasus: PT WY). 2015, 173-177. 